\title{
Environmental safety of the air transport: the problems and the solutions
}

\author{
E. E. Rumyantseva ${ }^{1, *}, A . V$. Gubenko ${ }^{2}$, and $A$. R. Pankratova ${ }^{2}$ \\ ${ }^{1}$ Economic Policy and Business Center, Moscow, Russia \\ ${ }^{2}$ Federal State Budgetary Educational Institution of Higher Education «Saint-Petersburg State \\ University of Civil Aviation», St. Petersburg, Russia
}

\begin{abstract}
This article presents the results of an interdisciplinary study of problems and ways to solve them in the field of ensuring the environmental safety of air transport in Russia and in the world, carried out by its authors. The environmental safety of air transport in Russia is provided in Russian legislation to a greater extent formally, but based on a rather deeply developed concept of "safety", covering all areas of life. Wherein, there is an acute lack of collection and publication of quantitative indicators on which development of this research topic shall be based, in the adopted regulatory legal acts there is inconsistency and lack of development is felt. The authors focus on the need for scientific research in Russia and preparation of regulatory legal acts at a new qualitative level as overcoming Russia's position as a catching-up country in this and a number of other areas, presenting new promising areas as a result of their scientometric work, including personal responsibility of passengers for reducing carbon emissions from their air travel.
\end{abstract}

\section{Introduction}

Being an important part of the transport sector, air transport provides convenient transportation and significant economic benefits, but it is also a major environmental pollutant. The greatest attention of the international community is paid to the problem of carbon emissions from air transport. In 2009, the International Air Transport Association (IATA) has launched an initiative to reduce carbon emissions by $50 \%$ by 2050 to 2005 levels. In 2016, the International Civil Aviation Organization (ICAO) drew attention to this initiative, indicating that without mitigation measures, carbon emissions from air travel will reach 2.6 billion tonnes by 2050 , which is $22 \%$ of the global total and will become almost 11 times more than the current level of pollution (about $2 \%$ ) [1]. ICAO recently adopted a "carbon neutral growth from 2020" resolution requiring $\mathrm{CO}_{2}$ emissions from international aviation not to exceed 2019-2020 levels [2].

The progress in ensuring the environmental safety of air transport is made up of the efforts of many countries around the world. Due to the fact that Russia is tacitly guided by the position of the catching-up country on this issue, which is also manifested in the approaches to settlement of territorial environmental problems [3] and the country's

\footnotetext{
* Corresponding author: e.p.centre@mail.ru
} 
orientation towards use of foreign-made air transport, it seems relevant to draw the attention of Russian researchers and authorities to these problems in order to raise the quality of their scientific developments and regulatory legal acts to a new level.

\section{Materials and methods}

Systematically, the topic of environmental safety of air transport is part of the safety concept currently applied in the Russian legislation and also one of the aspects of an integrated approach to ensuring the safety of air transport. The nationwide theoretical concept of safety, shared by Russian science, is sufficiently high-tech reflected in the Federal Law "On Safety", and considering the specifics of industry management, for example, in the Concept of the Federal Target Program "Ensuring the Flight Safety of Aircraft of the State Aviation of the Russian Federation in 2010-2014".

In Article 1 of the Federal Law "On Safety", environmental safety is part of the general concept of "safety" along with its other parts, the study of which is based on application of the following five principles of their provision that are common for all types of safety, namely:

observance and protection of human and civil rights and freedoms;

legality, i.e. legal certainty and control over their implementation;

consistency and complexity of application of political, organizational, socio-economic, informational, legal and other safety measures;

priority of planned preventive safety measures in comparison with emergency rescue;

interaction of federal bodies of state power, bodies of state power of the constituent entities of the Russian Federation, other state bodies with public associations, international organizations and citizens in order to ensure safety [4].

The extent to which these principles are implemented in the practice of ensuring the environmental safety of air transport is the subject of research in more than one scientific work, including the analysis of information sources for which there is an obvious deficit. However, even in the text of the Law itself, the concept of "environmental safety" is used only once, and its specificity, accordingly, is not disclosed. This determines the advisability of disclosing the essence of the concept and the mechanism for ensuring "environmental safety" in other regulatory legal acts, including the legal regulation of the activities of Russian air transport.

In the Concept of the federal target program "Ensuring the Flight Safety of Aircraft of the State Aviation of the Russian Federation in 2010-2014":

a fairly clear definition of the categories of "flight safety" and "hazardous factors" subdivided into internal and external ones (i.e., the leading role of the need to establish causal relationships and use of factor analysis in studies of air transport safety) is given;

the most common causes of accidents related to the actions or inaction of aviation personnel and/or the state (behavior) of the aircraft or flight support facilities were named;

the feasibility of creating a unified flight safety management system based on application of the standards and recommendations of the International Civil Aviation Organization was determined;

the most important role of quality and timeliness of collection, processing and analysis of complete and reliable information on the functioning of the air transport system that is part of the continuous monitoring of the effectiveness of the unified safety management system as a whole and its links is substantiated;

the unified safety management system also emphasizes the important role of aircraft accident investigations, information on which shall be concentrated within the framework of a single accident investigation center for the state aviation designed to identify and 
eliminate hazards even before it becomes necessary to consider them as the causes of aviation incidents.

Wherein, it was noted in this Concept that at the time of its development and adoption, achievement of such a level of safety within the framework of the main activities of the bodies responsible for development and functioning the state aviation was not ensured [5]. That is, as of 2009, at the official level, a significant problem of the insufficient level of ensuring the safety of flights of state aviation aircraft was recognized. However, at the same time, the concept of "environmental safety" has never been used in this document, which indicates insufficient attention to this problem and incompleteness of creation of the system of state and public control over implementation of regulatory legal acts, since information about the Concept of the Federal Target Program "Ensuring the Flight Safety of Aircraft of the State Aviation of the Russian Federation in 2010-2014" with establishment of the maximum (forecast) amount of financing of the Program from the federal budget in the amount of 11 billion rubles, were officially published, and the indicators of its implementation, including data on cancellation or prolongation, estimates its effectiveness is absent.

Wherein, in the State Program for Ensuring the Safety of Civil Aviation Aircraft, adopted a year earlier, one of the tasks of "achieving an acceptable level of flight safety" is "to ensure a systematic approach to identifying hazard sources and controlling risk factors to minimize the number of human casualties, as well as the size of material, environmental and social damage". It is clear that the environmental safety of flights is not put in the first place in comparison with the preservation of human lives, but it is nevertheless considered in this document along with property and social damage. However, within defining safety management, along with minimizing human casualties, property damage, financial ones are added to the social and environmental consequences. That is, even one state document contains inconsistencies and contradictions between conceptually important formulations of related parts - definition of safety management, which (according to the requirements of science) shall include the most important features of the concept, and one of the tasks, the wording of which shall not coincide with the definition. At the same time, in this document, the adjective "ecological", except for the above two fragments, is not used anywhere else, and, accordingly, the mechanism for minimizing environmental damage is not considered, which is one of the reasons that it is still substantially incompletely implemented in practice [6].

The report of the Federal Air Transport Agency "On the Results of the Work of the Federal Air Transport Agency in 2019, the Main Tasks for 2020 and for the Medium Term" does not reflect the problem of the environmental safety of air transport in any way, even purely formally and fluently, which indicates an underestimation of significance of this complex problems for Russia in the current activities of the federal authority responsible for development of this industry [7].

These and other regulatory legal acts that do not consider the environmental safety of air transport as the most important direction of state policy in compliance with achievements of the world and all-Russian theory of effective management - from goal-setting to assessing their implementation with the transition from it to the next stage of goal-setting, at the same time significantly emphasize attention to the main methods that shall be used not only in fundamental scientific research, but also in current analytical activities - systemic and integrated approaches, causal and factor analysis, fundamental principles of safety assurance, including in relation to the environmental safety of air transport. 


\section{Results and discussion}

Despite the significant shortcomings while reflecting the problems of ensuring the environmental safety of air transport in the regulatory framework, which, according to researchers [for example, 8], cannot be considered complete, and the search for ways of sustainable development of air transport in Russia has not yet been completed [9], the Transport strategy of the Russian Federation for the period up to 2030, among the tasks aimed at achieving goal 6 "Reducing the negative impact of the transport system on the environment" sets "increasing environmental requirements for aircraft (in terms of noise and emissions)" and also "introduction of new environmentally friendly clean substances for aviation technologies, reduction of use of harmful substances, development of technologies for their utilization, implementation of research programs in the field of aviation biofuels". Appendix 3 to this Strategy provides a change (in relation to the level of 2011 ) in the number of quantitative indicators for achieving goal 6 "Reducing the negative impact of the transport system on the environment" for air transport in two ways:

on an innovative option

first level indicators

1. the volume of $\mathrm{CO}_{2}$ emissions per one reduced t-km - up to $66 \%$;

2. the volume of emissions of air pollutants per reduced t-km - up to $60 \%$; second level indicators

3. average specific fuel/electricity consumption per one reduced t-km - up to $66 \%$;

4. the share of air transport organizations that have implemented environmental management systems for environmental quality management and environmental safety in transport in the total number of air transport organizations - an increase from less than $1 \%$ in 2011 to $100 \%$ in 2030 ;

according to the basic (conservative) option

first level indicators

1. the volume of $\mathrm{CO}_{2}$ emissions per one reduced t-km - reduction up to $80 \%$;

2. the volume of emissions of air pollutants per reduced ton-km - reduction of up to $70 \%$;

second level indicators

3. average specific fuel/electricity consumption per one reduced t-km - reduction up to $80 \%$;

4. the share of air transport organizations that have implemented environmental management systems for environmental quality management and environmental safety in transport in the total number of air transport organizations - increase from less than $1 \%$ in 2011 to $95 \%$ in 2030 [10].

As follows from the data provided, the two options considered in the Transport Strategy of the Russian Federation have significant differences and, of course, lead to different levels of environmental safety of air transport, which, in our opinion, are seriously underestimated - indicators of environmental safety of air transport could be much higher in the context of a closer integration of the Russian government and science.

Of course, not only the planned indicators provided in the two options are of interest, but also their implementation. Reports on implementation of the Transport Strategy of the Russian Federation for 2015-2020 have been published on the website of the Ministry of Transport of the Russian Federation, which provide some selected indicators for achievement of goal 6. For example, the Report for 2020 provides some (not all) indicators for rail and road transport only. It is specified that these indicators are provided by official statistical observation. There are no data to check the planned indicators for the environmental safety of air transport in the Report for 2020, that is, monitoring of their 
implementation has not started and is not reflected in any way [11]. The problem of the published information reliability is also important [12].

Our analysis shows that the Russian legislation has not yet implemented a systematic and integrated approaches to ensuring the environmental safety of air transport, and research developments in this area have not been fully considered. For example, an international group of researchers offers to develop transport projects based on the methodology of balancing economic interests and negative environmental and social consequences [13]. Spanish researchers provided a dynamic analysis of changes in $\mathrm{CO}_{2}$ emissions in the European Union as a result of renewal of the aircraft fleet [14], which, in our opinion, may be required for monitoring the implementation of the Transport Strategy of the Russian Federation for this first level indicator. E.Yu. Starkov and N.I. Nikolaikin focus attention on the problems of emergency volley environmental impact at aviation catastrophes by offering a range of measures to reduce the negative impact on the environment of this part of the environmental safety of the air transport system, along with the problem of $\mathrm{CO}_{2}$ emissions and thereby negative impact to climate change [15]. Australian researcher M. Mkono draws attention to the environmental movement of citizens who refuse to fly on airplanes that emerged in 2018 in Sweden (including publicly, attracting media attention) due to implementation of their civil liability for the negative impact of air travel on the environment [16]. M. Mkono and a number of other foreign researchers believe [17] that the participants in this movement have a distorted perception of the impact of air transport on the environment, and, in general, condemn intervention of society in specific issues of industry development. Other researchers, opposing the negative attitude to the movement of flight refusals due to climate change, on the contrary, conclude that the increased awareness of citizens as one of the stakeholders in reducing toxic air emissions from air travel and their impact on formation of long-term climate policy [18]. These publications represent a completely new direction of research in Russia, initiating development of an analysis of the interaction of the state, airlines and passengers in resolving the most complex problems associated with ensuring the environmental safety of air transport in terms of accelerating their scientific developments and solutions. According to the American researcher K. Button, environmental damage from air transport is often associated with serious government failures [19]. In this regard, the positive role of public institutions, influencing adoption of more elaborated government decisions on the basis of an open discussion, seems obvious. This conclusion is also confirmed by a group of American researchers who identified 10 criteria for prioritizing stakeholders when making decisions in the field of environmental management [20], which is also relevant for analyzing the decision-making system to ensure the environmental safety of air transport. Wherein, the above critical publications do not disclose the history of formation of the movement of refusal of a number of active citizens with a sense of personal responsibility from flights, which was preceded by experiments on introducing voluntary monetary compensation for carbon emissions for passengers of some airlines: some airlines have introduced voluntary quotas on carbon emissions, which can be purchased by passengers, giving them the opportunity to pay offsets for carbon emissions arising from their personal air travel. From December 2010 to January 2011, 1,339 Taiwanese air passengers were polled at Taoyuan International Airport on their willingness to pay for carbon offset [21].

In Australia, voluntary carbon offset programs for the aviation sector were part of the Clean Energy Future Plan and a carbon tax from July 1, 2012 to July 17, 2014, which was canceled due to severe political changes [22]. According to the survey conducted in Malaysia, $71 \%$ of households were willing to financially participate in the carbon reduction program to improve the environment and protect the climate [23]. According to the survey of 1,228 Italians, they are willing to pay compensation for their carbon footprint in the environment from use of air transport, and this willingness ranges from 12 to 38 
euros per tonne and from 14 to 66 euros per flight [2]. ICAO developed a method of calculating carbon dioxide emissions as a result of air travel for use in compensation programs and, moreover, provided the possibility for any person wishing to calculate online calculator carbon $\mathrm{CO}_{2}$ emissions per passenger. According to these calculations, carbon emissions within Moscow-Anapa flight per passenger are $116.9 \mathrm{~kg}$ [24], which makes one think not only of the world's governments loaded with various issues, but also of citizens outside the system of government and, of course, contributes to combining the efforts of different stakeholders.

\section{Conclusions}

Despite the fact that for several decades the topic of environmental safety of air transport has been reflected in international and Russian legislation and is included in educational standards, and has been developing in applied terms, not enough attention has yet been paid to it in Russia. In our opinion, the environmental safety of air transport shall be provided in modern Russian legislation as one of the constituent parts of the concept of "safety of air transport" (in its definition) with the appropriate disclosure of each of the parts in accordance with the theoretical concept of safety and environmental management standards adopted in Russia and in the world. In the field of science, it is of interest for Russian researchers to involve in development of new scientific directions supported by researchers from different countries of the world, including the discussion of details of problems and measures to limit the negative impact of air transport on the environment, the procedure for interaction of interested parties, including passengers, and etc.

\section{References}

1. R. Qiu, S. Hou, Z. Meng, Transport Policy, 107, 1 (2021)

2. L. Rotaris, M. Giansoldati, M. Scorrano, Transportation Research Part A: Policy and Practice, 142, 71 (2020)

3. E. E. Rumyantseva, A. G. Bezdudnaya, M. G. Treiman, Problems of Modern Economics, 2(70), 195 (2019)

4. Federal Law of December 28, 2010 No. 390-FZ (as amended on November 09, 2020) "On Safety", The original text was published in the Corpus of Legislation of the Russian Federation, January 03, 2011, No. 1, Art. 2

5. The concept of the federal target program "Ensuring the Flight Safety of Aircraft of the State Aviation of the Russian Federation in 2010-2014" approved by Order of the Government of the Russian Federation of April 22.04.2009 No. 554-r. Corpus of Legislation of the Russian Federation, May 11, 2009, No. 19, Art. 2354

6. State program for ensuring the safety of flights of civil aviation. Approved by Order of the Government of the Russian Federation of May 06, 2008 No. 641-r. Corpus of Legislation of the Russian Federation, May 19, 2008, No. 20, Art. 2373

7. Report of the Federal Air Transport Agency "On the Results of the Work of the Federal Air Transport Agency in 2019, the Main Tasks for 2020 and for the Medium Term", https://favt.gov.ru/

8. P. N. Ishmuratov, Administrative Law and Process, 6, 58 (2014)

9. A. V. Gubenko, Yu. I. Rastova, A. R. Pankratova, Scientific Magazine of National Research University of Information Technologies, Mechanics and Optics, 2, 82 (2019) 
10. Transport strategy of the Russian Federation approved by Order of the Government of the Russian Federation of November 22, 2008 No. 1734-r. Corpus of Legislation of the Russian Federation, December 15, No. 50, Art. 5977

11. Report on implementation of the Transport Strategy of the Russian Federation for the period up to 2030 for 2020. Published on August 20, 2021. Official website of the Ministry of Transport of Russia, https://mintrans.gov.ru/

12. E. E. Rumyantseva, Modern management: problems and prospects. Collection of articles on the results of the XVI international scientific and practical conference (St. Petersburg, 2021), 81

13. K.-J. Wu, M.-L. Tseng, M. H.,Ali, B.Xue, A. S. F. Chiu, M. Fujii, M. Xu, S. Lan, M. Ren and Y. Bin, Environmental Impact Assessment Review, 88 (2021)

14. F. Amizadeh, G. Alonso, A. Benito, G. Morales-Alonso, J. of Air Transport Management, 55, 9 (2016)

15. E. Yu. Starkov, N. I. Nikolaykin, XXI century: the results of the past and the problems of the present plus, 2, 13 (2016)

16. M. Mkono, J. of Tourism Futures, 6(3), 223 (2020)

17. P. Chiambaretto, E. Mayenc, H. Chappert, J. Engsig, A.-S. Fernandez, F. Le Roy, J. of Air Transport Management, 93 (2021)

18. S. Gössling, A. Humpe, T. Bausch, J. of Cleaner Production, 266 (2020)

19. K. Button, J. of Air Transport Management, 26, 1 (2013)

20. L. M. Sharpe, M. C. Harwell, C. A. Jackson, J. of Environmental Management, 282, 15 (2021)

21. J.-L. Lu, Z. Yi Shon, Transportation Research Part D: Transport and Environment, 17(2), 124 (2012)

22. A. S. Choi, S. Gössling, B. W. Ritchie, Transportation Research Part D: Transport and Environment, 62, 225 (2018)

23. M. M. Masud, Quasem A. Al-Amin, R. Akhtar, F. Kari, R. Afroz, M. S. Rahman, M. Rahman, J. of Cleaner Production, 89, 41 (2015)

24. ICAO Carbon Emissions Calculator, Official site of ICAO, https://www.icao.int/ 